\title{
SPATIAL DIFFERENT ANALYSIS OF LAND USE/LAND COVER CHANGE AND HUMAN IMPACT IN TYPICAL OASIS IN ARID LAND
}

\author{
Hongwei Wang $^{1,2}$, Tash polat Tiyip ${ }^{1,2, *}$, Jianli Ding ${ }^{1,2}$, Jiangyan Luo ${ }^{1,2}$ \\ ${ }^{1}$ Xinjiang University College of Resources and Environment Science, Urumqi,Xinjiang Uygur \\ Autonomous Region.China, 830046 \\ 2 Key Laboratory of Oasis Ecology, Ministry of Education,Urumqi,Xinjiang Uygur \\ Autonomous Region. China, 830046 \\ * Corresponding author, Address: Xinjiang University College of Resources and Environment \\ Science,Urumqi,Xinjiang Uygur Autonomous Region.China,830046,Tel:+86-991-8582817, \\ Email:tash@xju.edu.cn
}

Abstract: With the current problem of population,resources and environment becoming increasingly intense day by day, the land use/land cover change (LUCC) is one of the core topics on the Present World Change Study.And with the worsening of the global environment,the exhausting of energy and the population explosion, the controversy between the development of oasis economy and the environment has become more and more sharp,which has formed a serious threat to the sustainable development the oasis economy.As a result,the reasonable,coordinate and continuous development is the experimental topic with great theoretical and practical significance in the world.Land use/land cover (LUCC) change has vital significance in environmental variation and the ecology monitoring in the arid and semi-arid areas.This article selects the typical oasis of Awat oasis, which is located in the upstream of Tarim River, where is a typical ecological fragile zone and environmental critical zone.Many effects are caused by the utilization of land and water resources.Along with further development and utilization,great changes of LUCC have been taken place.Based on the research on oasis-desert ecosystem, with the frontier theory of physical geography,LUCC of Awat oasis from 1990 to 2002 are analyzed through the technological train of $3 \mathrm{~S}$ and statistics, and established the human impact index.Its influencing factors are also identified.First we take the farmland,the wood land,lawn,water,resident,wetland,salt alkali,sand land and naked land as a classification system.Based on the detailed analysis and pretreatment to the remote sensing imagery,we obtained reatively high precision classification

Please use the following format when citing this chapter:

Wang, H., Tiyip, T.P., Ding, J. and Luo, J., 2009, in IFIP International Federation for Information Processing, Volume 293, Computer and Computing Technologies in Agriculture II, Volume 1, eds. D. Li, Z. Chunjiang, (Boston: Springer), pp. 387-397. 
result.By the quantification research of human impact to LUCC in Awat,it can be divided into the high human impact area and the low human impact area.The research shows that the changes of pattern are notable and human impact is continuously enhanced,and which is important for the sustainable development of Awat oasis.This research presents the evidence for harmonizing the relations between the land resource and the human activity and provides some methods and experiences for further study of LUCC in arid region.

Keywords: Land Use/Land Cover,human impact,spatial different,Awat Oasis

\section{INTRODUCTION}

Land use is an important factor of land cover change, and land cover change acts on land use in reverse.As the basis of human existing,and the main object of agricultural production, the status of land use/land cover not only influences the natural basis of human survival and development,but also closely relates with global climate change,evolution of the ecological environment,and the continuable connection between humanity and the environment that interacted with each other.So the land use/land cover is one of the main reason of global environment changes at present,and the core of all sustainable development either(Zhang Ming,et al.,2001;Bai Wanqi,et al.,2001; Tash polat Tiyip,et al.,2006;Li Xiubin,et al.,2002).

In the areas that sensitivity respond to environment, the strong interference from outside would result in abnormal change in ecological environment system. And the chain reaction of abnormal changes will be completely or partially change the natural environment(Louis-Albert Lake,et al.,2003;Marq De Villier,et al.,2002).People's role present many prominent impact on the Earth system by the complexity way,these effects interacted with themselves,as well as performance multi-pattern changes in local and regional scale,and make us unintelligibly,even difficult to forecast,and the mutation often occurred.Many academics at home and abroad have discussed the mechanism and laws of this change from many aspects(LouisAlbert Lake,et al.,2003;Marq De Villier,et al.,2002;Zhang Bo,et al.,2006;Du Lingtong,2007).The south oasis of XinJiang is the region that human activity frequently and tempestuously,and it has an unique combination of community-economy-nature as well as the ethical culture. Quantitative research on driving force factors about LUCC in arid region are peopitious to the in-depth understanding of this system,clarifying the driving force mechanism of the land use change in arid region would lay a foundation for quantitating research on oasis stabilization,regional population,sustainable development of resources and environment. 


\section{LOCATION AND ENVIRONMENT}

Awat County lies in the midwest of Xinjiang Uygur Autonomous Region and in the northeast of The Tarim basin,and south of the Tianshan Montain.Locates north latitude $39^{\circ} 31^{\prime}$ to $40^{\circ} 50^{\prime}$, east longitude $79^{\circ} 45^{\prime}$ to $81^{\circ} 05^{\prime}$.This region major includes the Awat Country in Aksu Prefecture,and the area is $1.3 \times 104 \mathrm{~km}^{2}$.The terrain is flat,and the north and the middle part are alluvial plain which belong to water landscape;and the south is desert plains the belongs to aeolian landforms. The climate here is warm temperate zone and arid weather of mainland.Aksu River,Yarkand River and the Hotan River intersect here,forming China's largest inland river---Tarim River.The economic development of this region mainly depends on agriculture,and that is an important grain and cotton bases of Xinjiang.But because of overdevelopment causing the local ecological environment deteriorated,also has a certain impact on backward position.

\section{METHODS}

\subsection{Data Acquisition}

We selected Landsat TM data of the research region in May 1990 and in August 2002 as the main remote sensing data source and the 1:50000 digital grid map which is produced by National Foundation of Geography Information Centers and State Bureau of Surveying and Mapping.We then used the registration and geometric correction for ENVI 4.3 to geometrically correct, which made allowed the TM to match the base picture.We extracted the geographical information of the remote image by visual interpretation and use of maximum likelihood supervised classification on the basis of land using map. Selecting point from the results of interpretation at random to verify the accuracy,GPS points' attribute checking results show that land use types determine the accuracy rate of above $95 \%$.The Arcgis 9.0 system was used to complete editing and revision of the resulting data.The data were then used to produce the vector map to obtain two group of data about land use;land types' division should reflect the western arid area oasis-desert ecosystem basic characteristics, and make the interpretation of remote sensing dates as the classification standards of land use,combining the characteristics of the research area,land use types can divide into nine categories: farmland, forestland, grassland, water area, residential area, wetlands, salinity, sandlot, bare areas. 


\subsection{Land use/Land cover Classification Index and Its Calculate Methods}

In this research we introduce landscape ecology factor to statute and analyse the LUCC through Fragstats For Arcview.Although many landscape indexes have been published(Wu Jianguo,2000;Li Habin,et al.,1992; Chen Linding,et al.,1996; Wang Genxu,et al.,1999),we used the indexes listed in Table1 to evaluate changes in landscape pattern.

Table1. Landscape indexes and their formula

\begin{tabular}{|c|c|c|}
\hline Landscape indexes & Abbreviation & Formula \\
\hline Number of patches & NP & $N P=N$ \\
\hline Class area & CA & $C A=\sum_{j=1}^{n} a_{i j}$ \\
\hline Total area & TA & $T A=A$ \\
\hline Mean patch size & MPS & $M P S=A / N$ \\
\hline Percentage of landscape & PLAND & $P L A N D=P_{i}=\frac{\sum_{j=1}^{n} a_{i j}}{A} \times 100 \%$ \\
\hline Landscape diversity index & $\mathrm{H}$ & $H=-\sum_{i=1}^{m}\left[P_{i} \cdot \ln \left(P_{i}\right)\right]$ \\
\hline Landscape evenness index & $\mathrm{E}$ & $E=H / H_{\max } ; H_{\max }=\ln (m)$ \\
\hline Landscape dominance index & $\mathrm{D}$ & $D=H_{\max }+\sum_{i=1}^{m}\left[\left(P_{i}\right) \cdot \ln \left(P_{i}\right)\right]$ \\
\hline Landscape isolation index & $\mathrm{S}_{\mathrm{i}}$ & $S_{i}=D_{i} / B_{i} ; \quad D_{i}=1 / 2 \sqrt{\frac{n_{i}}{A}} ; \quad B_{i}=A_{i} / A$, \\
\hline Landscape fragmentation index & $\mathrm{C}$ & $C=N / A ; \quad C_{i}=n_{i} / A_{i}$ \\
\hline
\end{tabular}

Where: $N$ is the quantity of patch, aij is the total area of all patches in the landscape type I,A is the landscape's total area,Pij is each patch's circumference, the $m$ is the total amount of a type of patch in landscape, the Pi is the rate that a type of patch $i$ appear in the landscape,the ni means the total patch within the landscape type $i$.

\subsection{Human Impact Index}

The result of human activity is the primal and natural characteristics of land type falling down continually,different land types represent different human activity or the intensity of development and utilization characterstics(Wang Zhengquan,1999).Then according to the characteristics of the type of land use, we construct an human impact index to describe the intensity of human impact in a certain region. The calculate formula as below:

$$
H A I=\sum_{i=1}^{N} A_{i} P_{i} / T A
$$

Where,HAI is human impact index,N is the quantity of land use patch,Ai is the total area of all patches in the land use type I,Pi is the strength of the 
human impact which reflected by land use components, TA is the total area of land use.

The strength indexes of human impact reflects the strength and attributes characterstics of different components of human involvement,management, transformation.In this study,Delphi methods is adopt to confirm the index(Table.2).HAI changes between 0 and 1 , and the more the HAI is, the bigger human activities in the ascendant of land use are,and the bigger of human impact is, and vice versa.

Table 2. The strength indexes of human impact for different land use

\begin{tabular}{cccccccccc}
\hline $\begin{array}{c}\text { Land } \\
\text { use }\end{array}$ & Farmlan & Forestlal & Grassland & $\begin{array}{c}\text { Water } \\
\text { area }\end{array}$ & $\begin{array}{c}\text { Residentia } \\
\text { l area }\end{array}$ & Wetland & Salinity & Sandlot & $\begin{array}{c}\text { Bare } \\
\text { area }\end{array}$ \\
\hline Delphi & 0.54 & 0.09 & 0.24 & 0.12 & 0.96 & 0.15 & 0.38 & 0.24 & 0.08 \\
\hline
\end{tabular}

\subsection{Spatial analysis}

The human impact index has the charactertics of spatial variability,so can use the geostatistics methods to analyse the spatial charactertics. The geostatistics is the methods of analysing the questions about spatial variable,basing on typical statistics, and considering the spatial variable and the spatial changes charactertics sufficiently(relativity and randomicity), and taking variograms as tool(Wu Jianguo,2000; Wang Genxu,et al.,1999).Geostatistics can describe the human impact index of spatial structure clearly,thereby,can deeper understand the land use types which affected by spatial distributing and gradient changes and directional characteristics of humans'development and utilization,and using spatial interpolation methods can express the human impact status quantificationally as picture(Chen $\mathrm{Fu}$,et al.,1999).

This research used the Kriging methods of geostatistics mainly, that is based on variogram theory and structural analysis.If the result shows relevance of space among the regional variables, then we can utilize the original data of regional variable and the frame of semi-variance function to evaluate the date that is linearly and optimally estimated without bias.Compare with normal methods,its advantage is maximize using the spatial information.

To ensure the human impact index of geostatistics can deputy the total status of human activities in certain area,in this paper,we used all the work area of grid for system sampling,each sample deputy as human activity, and the result as the center of samples.Generally believed that the type of land use should be 2-5 times of the mean patch size,then can reflect the pattern information of sampling area(O'neill R V,1996).According to the actual size of land use pattern patch in Awat Country,determining the sampling grid is $7 \mathrm{~km} \times 7 \mathrm{~km}$. 
On the basis of variograms,using ArcGis9.0 and block kriging produced the strength picture of human impact,so that we can discribe the spatial distribution of human impact directly in research area.

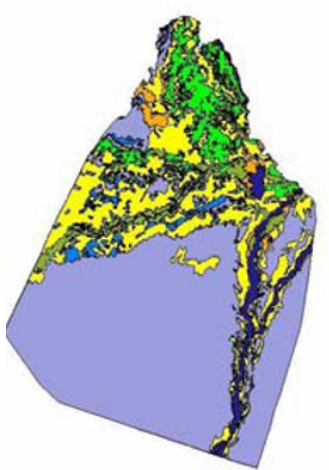

1990
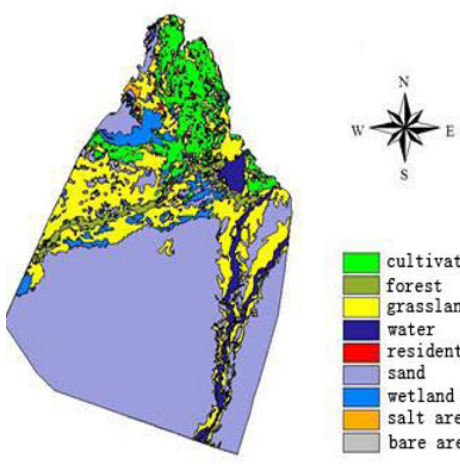

cultivated land forest grasslands water residental area rand wetland salt area bare area

\section{CONCLUSION AND ANALYSIS}

Awat oasis is a typical desert oasis which locates in west-arid region and lies upstream areas of Tarim River,its basic pattern is desert-oasis-river,as the Fig. 1 express. The tab. 3 and tab.4 reveals the land use/land cover of total landscape pattern and the changes of patches' eigenvalue.

Table 3. Changes of characteristic values of landscape pattern in research area from 1990 to 2002

\begin{tabular}{lcc}
\hline \multirow{2}{*}{ Index } & \multicolumn{2}{c}{ Eigenvalue } \\
\cline { 2 - 3 } & \multicolumn{2}{c}{$1990 \mathrm{~s}$} \\
\hline TA $\left(\mathrm{hm}^{2}\right)$ & 853 & 1295556.76 \\
NP & 1518.8239 & 753 \\
MPS $\left(\mathrm{hm}^{2}\right)$ & 1.3018 & 1720.5269 \\
H & 0.5925 & 1.2805 \\
E & 0.8954 & 0.6158 \\
D & 0.0658 & 0.7989 \\
C & & 0.0681 \\
\hline
\end{tabular}


Human Impact in Typical Oasis in Arid Land

Table 4. Changes of characteristic values of landscape patches in research area from 1990 to 2002

\begin{tabular}{|c|c|c|c|c|c|c|c|}
\hline Landscape & Year & NP & TA $\left(\mathrm{hm}^{2}\right)$ & MPS (hm2) & PLAND (\%) & $\mathrm{Si}$ & $\mathrm{C}$ \\
\hline \multirow{2}{*}{ Farmland } & 1990 & 60 & 86568.96 & 1442.8160 & 6.6820 & 0.0509 & 0.0007 \\
\hline & 2002 & 50 & 119779.27 & 2395.5854 & 9.2454 & 0.0336 & 0.0004 \\
\hline \multirow{2}{*}{ Forestland } & 1990 & 174 & 77117.4 & 443.2034 & 5.9525 & 0.0595 & 0.0023 \\
\hline & 2002 & 104 & 40637.97 & 390.7497 & 3.1367 & 0.0314 & 0.0026 \\
\hline \multirow{2}{*}{ Grassland } & 1990 & 172 & 285118 & 1657.6628 & 22.0074 & 0.2201 & 0.0006 \\
\hline & 2002 & 148 & 279219.63 & 1886.6191 & 21.5521 & 0.2155 & 0.0005 \\
\hline \multirow{2}{*}{ Water area } & 1990 & 49 & 42576.19 & 868.9018 & 3.2863 & 0.0329 & 0.0012 \\
\hline & 2002 & 36 & 42311.98 & 1175.3328 & 3.2659 & 0.0327 & 0.0009 \\
\hline \multirow{2}{*}{$\begin{array}{l}\text { Residential } \\
\text { area }\end{array}$} & 1990 & 73 & 854.27 & 11.7023 & 0.0659 & 0.0007 & 0.0855 \\
\hline & 2002 & 195 & 6011.42 & 30.8278 & 0.4640 & 0.0046 & 0.0324 \\
\hline \multirow{2}{*}{ Wetland } & 1990 & 76 & 739622.27 & 9731.8720 & 57.0891 & 0.5709 & 0.0001 \\
\hline & 2002 & 103 & 742886.65 & 7212.4917 & 57.3411 & 0.5734 & 0.0001 \\
\hline \multirow{2}{*}{ Salinity } & 1990 & 163 & 35801.91 & 219.6436 & 2.7634 & 0.0276 & 0.0046 \\
\hline & 2002 & 92 & 58521.54 & 636.1037 & 4.5171 & 0.0452 & 0.0016 \\
\hline \multirow{2}{*}{ Sandlot } & 1990 & 78 & 27661.65 & 354.6365 & 2.1351 & 0.0214 & 0.0028 \\
\hline & 2002 & 25 & 6188.23 & 247.5292 & 0.4777 & 0.0048 & 0.0040 \\
\hline \multirow{2}{*}{ Bare area } & 1990 & 8 & 235.1 & 29.3875 & 0.0181 & 0.0002 & 0.0340 \\
\hline & 2002 & 0 & 0 & 0 & 0 & 0 & 0 \\
\hline
\end{tabular}

\subsection{Analysis on Land use / Land cover changes in landscape scale}

According to Table 3 and Table 4,land use pattern of Awat oasis changed obviously between 1990 and 2002.From the analysis of the TM digital images extraction, the total area of land use is $1295556.76 \mathrm{hm}^{2}$, the number of patch reduce between 1990 and 2002, and corresponding average area of patch is increasing from $1518.8239 \mathrm{hm}^{2}$ to $1720.5269 \mathrm{hm}^{2}$, the added value is $201.703 \mathrm{hm}^{2}$.Shannon deversity index reduce from 1.3018 to 1.2085 , but Shannon evenness index increase from 0.5925 to 0.6158 . The decrease of dominance index indicates that the landscape structure of the whole area is controled by some types of patches which has roughly equal proportion. Besides sandlot, farmland and grassland also have effect in controlling the whole landscape dynamically. The fragmentation of the landscape is in the tread of increased indicate that the interferance of human is becoming harder.

\subsection{Analysis on Land use / Land cover changes in patch scale}

In study area, sandlot remains as the basic of landscape, accounting more than half of the total area.Between 1990 and 2002, its area increased by about $3.26 \times 10^{3} \mathrm{hm}^{2}$, the patch number increased from 76 to 103 . Usually in environmental governance,only when the patch area and patch number become less and less, the strength of fragmentation about landscape type enhance constantly, can increase the degree of human environmental 
governance to meet the requirements.Sandlot's pattern of the index can reflect changes when the local ecological environment hazards increasing.

The insides of Oasis,farmland,forestland and grassland larger in area.In 12 years,farmland area increased $3.32 \times 104 \mathrm{hm}^{2}$, but the patch number changed little. Local farmers deforestated,destructed the grass and reclamated incessantly,so the area of artificial oasis expanded rapidly. The complexity of the patch had decreased,and their fragmentation and separation showed a downward trend, either.This was mainly due to the increasing area of farmland patch,the patch tend to be joint.Meanwhile,forestland and grassland continued to reduce,mostly assart as farmland,and were impacted by human activities increasingly,the instability enhanced.

The most obvious change is in the residential area.The number of patch is the most among all the types of landscapes, and increases to 122 during 12 years.Its area has expanded more than seven times.Artificial oasis area increasing, and the number of population growing rapidly affected settlements changes directly. So we can get that the shape of the residential area tends to rule, and the complexity declines,and the artifical landscape charactertics tend to prominence.

The wetland landscape,which received more and more attention in recent years, has many kinds of natural functions such as regulating regional climate, cleanning up the environment and maintainning the regional water balance,etc. However,the number of the wetland patch in the study area decreased from 163 to 92 during 12 years, the area increased.By contrast, the number of water body patch changed little and the area declined slightly.In practice, its natural waters' area reduced unceasingly, the regional water consumption increases leading to decline of the runoff and the expansion of artificial reservoirs made the proportion of the artificial waters to increase, thus the waters'overall change is not obvious.

The issue of soil salinization of the research area has improved during the 12 years.There is a large area of saline-alkali soil in the oasis interior and Oasis-desert transitional zone.The number and size of saline-alkali soil has a declining trend,accounted for the landscape proportion from $2.1351 \%$ in 1990 to $0.4777 \%$ in 2002 .

Through the above analysis we can see that different types of landscape pattern index does not change with the overall change trend in sync.This shows changes in landscape pattern has the instability and the politropism characteristic, on the other hand also shows the human's operational flexibility in the future landscape pattern planning.Meanwhile the changing characteristics also demonstrated that it needs as many as possible interval materials to reveal the dynamic changes of the landscape pattern in trends and characteristics. 


\subsection{The spatial structure and distribution of human impact index}

The human impact spatial analysis is completed by the geo-statistical method, which is based on sampling and caculating the experimental variable function of the human impact index and then fitting the theoretical semi-variable function. In the semi-variable function, since the results of spherical model is more satisfactory,the structure analysis of human impact index mainly based on spherical model,within the scale,the spatial distribution of all elements are self-correlated and the main ecology function,procession and pattern are all correlated with the scale.

Fig.2 is the study area's human impact index distribution figure,which is acquired by inserting the data based on the variable function analysis.It shows that,the man-made oasis system whose capital is Awat was highly affected by human,this region keeps the traditional agricultural landscape,the main form of human activity is the agricultural production.Human activities transform from a single agricultural production to the diversification of agricultural production, and the traditional agricultural landscape transform into a county and suburb hybrid landscape.Vast grassland,dene,and parts of water are nearly not influenced by human activity. Since the climate environment in the area is relatively poor,the influence of human activities is still in a relatively small state. But the trend is extending.Comparing the human-impact characteristics in 2002 to 1990 , it has changed a lot,the highly influenced area has the current of sprending to the edge of the capital.The influence of human activities to Awat's land use is becoming larger and larger.

According to caculating the human impact index,we can see the highest data in 1990 is 0.529 and it is 0.577 in 2002.During the 12 years, the range of the human impact index extended and the degree of the human impact index increased too.At the sametime, it can be found from the figure that:(1) the nearer the distance to the capital is, the higher the index is,and the furtuer the distance is, the lower the index is:(2) along the tarim drainage basin,the index is larger, while the index of the region far from the basin is low. 


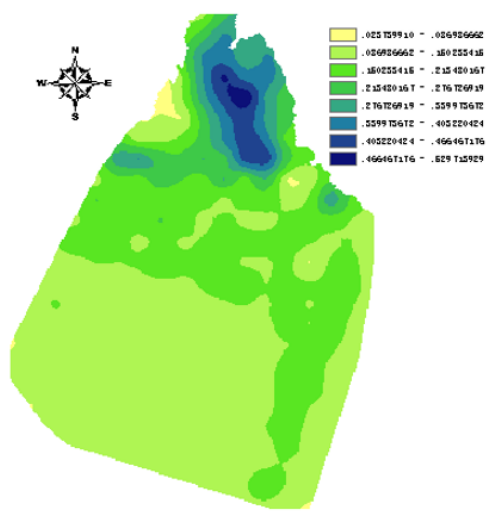

1990

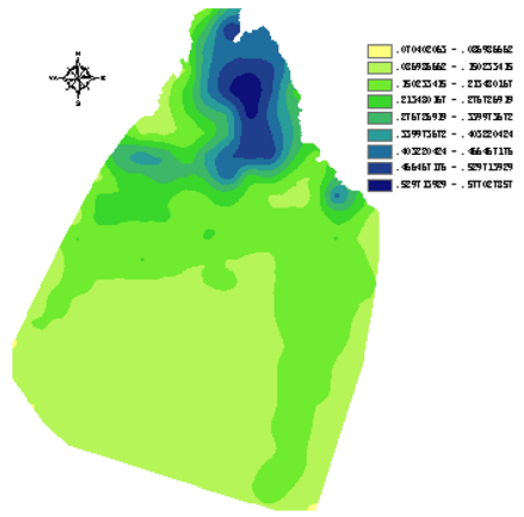

2002

Fig.2: Spatial distribution of human impact indexes

\section{CONCLUSION AND DISCUSSION}

The unique soil and water conditions of the Awat oasis,which located in the upper reaches of the Tarim River,determine its suitability in the agricultural and livestock production.After the development of more than 50 years,artificial oasis formed gradually and at the same time the human development and utilization of regional land and water resources constantly expanding outward.Research shows that land-use pattern has undergone tremendous changes in the study area in 1990-2002:the landscape heterogeneity of the entire study area is declining,the degree of fragmentation is increasing.That indicates high development of the artificial oasis becomes the main type of landscape and human influences on ecological landscape is strengthening. Through the measurement of human's activity index and spatial analysis, the highly influenced area by man's activity is expanding unceasingly and the human influences on land-use of Awat County is becoming larger.

How to quantify the influence of human activity on land-use/cover changes is the hot issue of LUCC.Through constructing the man's activity index of LUCC and spatial quantifying of the consequence in this study,gaining the human impact of changes in spatial variation and provides a valuable reference for further study on the relationship between human activities and the LUCC. 


\section{REFERENCES}

Bai Wanqi,Zhao Shidong.An analysis on driving force system of land use changes.Resources Science,2001,23(3),39-41.

Chen Fu,Li Manchun,Zhou Yinkang,Zhou Feng.Analysis of the spatial distribution pattern of urban land price with Geostatistics.Journal of NanJing University:Nat Sci Ed,1999,35(6),729-723.

Chen Linding,Fu Bojie.Analysis of impact of human activity on landscape structure in Yellow River delta----A case study of Dongying Region.Acta Ecologica Sinica,1996,16(4),337-344.

$\mathrm{Du}$ Lingtong.Land use/cover change in Yinchuan City based on RS technology.Arid Land Geography,2007,30(4),585-589.

LI Habin, WU Yegang.Quantitative Methods in Landscape Ecology. Science and Technology of China Press, Beijing, 1992, 209-234.

Li Xiubin,Explanation of land use changes.Progress in Geography,2002,21(3),195-203.

Louis-Albert Lake,Ngor Ndour,Mandiaye Thiobane. Dynamique de la répartition des paysages ruraux dans le nord du Sénégal depuis le milieu de XXe siécle.Science planétaire/Sécheresse , 2003,14(1),5-13.

Marq De Villiers, Développement durable. Ressources hydrique en Afrique subsharienne, Fall.Automne,2002,52-58.

O'neill R V. Scale problems in reporting landscape pattern at the regional scale.Landscape Ecology,1996,11(3):169-180.

Tash polat Tiyip, Ring.Z, Ding Jian-li, et al. Analysis of Markov process of LUCC in oasis of arid area----A case of the Yutian Oasis.Arid Land Geography,2006, 29(4): 548-556.

Wang Genxu,Cheng Guodong.The spatial pattern analysis of landscape in arid inland river basin----A case study of the middle reaches of Heihe River.Journal of Lanzhou University(Natural Science),1999,35(1),211-217.

Wang Zhengquan.Geostatistics application in ecology.Scienc Press,Beijing, 1999.

Wu Jianguo.Landscape Ecology.Higher Education Press,Beijing.2000,99-109.

Zhang Bo,Mao Yan-cheng,Liu Jing-feng.Analysis driving forces of LUCC in Heihe middle reaches.Arid Land Geography ,2006,29(5),726-730.

Zhang Ming. The progress on comprehensive land sciences focused on land-use and landcover change.Progress in Geography ,2001,20(4),297-304. 